\title{
Ni(II)- and $\mathrm{Cu}$ (II)-Containing Heterocyclic Compounds with 4,4',6-trimethyl- 2,8-dithio-3,7-diazanonen-6-dithioamide-1,9 Obtained in Gelatin-Immobilized Matrices in the Template Synthesis Process
}

\author{
Oleg V. Mikhailov ${ }^{\star}$, Marina A. Kazymova ". Tatyana A. Shumilova" \& Laisan R. Vafina" \\ * Kazan State Technological University, K. Marx Street 68, +20015 Kazan. Russia \\ ${ }^{\#}$ Kazan State University. Kremlin Street 18, 420008 Kazan, Russia \\ Fax: (8432)365768, e-mail: omikh@cnit.ksu.ras.ru
}

\begin{abstract}
Soft template synthesis of metalheterocyclic compounds with 4,4',6-trimethyl-2,8-dithio3,7-diazanonen-6-dithioamide-1.9 in the triple systems $\mathrm{M}(\mathrm{II})$ - dithiooxamide- acetone ( $\mathrm{M}=$ $\mathrm{Ni}, \mathrm{Cu}$ ) in the nickel(II)- and copper(II)hexacyanoferrate(II) gelatin- immobilized matrices has been carried out.
\end{abstract}

\section{Introduction}

As it was shown in our previous work [1], low-temperature template synthesis occurs in the $\mathrm{M}(\mathrm{II})$ - dithiooxamide-formaldehyde triple system $(\mathrm{M}=\mathrm{Ni}, \mathrm{Cu})$ at the contact of corresponding metal(II)hexacyanoferrate(II) gelatin-immobilized matrices $\left(\mathrm{M}_{2}\left[\mathrm{Fe}(\mathrm{CN})_{6}\right]\right.$-GIM) with aqueous-alkaline solutions containing dithiooxamide and formaldehyde. Besides, dithiooxamide and formaldehyde are ligand synthons in this process. Another ligand synthon containing carbonyl group, is acetone $\mathrm{Me}_{2} \mathrm{CO}$. This paper is devoted to establishing whether such a template synthesis is observed in the triple $\mathrm{M}(\mathrm{II})$-dithiooxamide -acetone systems in the $\mathrm{M}_{2}\left[\mathrm{Fe}(\mathrm{CN})_{6}\right]-\mathrm{GIM}(\mathrm{M}=\mathrm{Ni}, \mathrm{Cu})$. We report that we have been able to perform such a synthesis in triple systems indicated and to obtain macrocyclic coordination compounds of $\mathrm{Ni}(\mathrm{II})$ and $\mathrm{Cu}(\mathrm{II})$ with a novel so far unknown (N,N,S,S) -tetradentate ligand -4,4',6 -trimethyl -2,8-dithio3,7-diazanonen- 6-dithioamide-1,9.

\section{Experimental}

Nickel(II)- and copper(II) metalhexacyanoferrate(II) GIMs were synthesized as described in [2-4].

Synthesis of $\mathrm{NiC}_{10} S_{4} N_{4} H_{14}$. This synthesis occurs on contact of $\mathrm{Ni}_{2}\left[\mathrm{Fe}(\mathrm{CN})_{6}\right]$ GIM with alkaline solutions ( $\mathrm{pH}=11-12)$ containing dithiooxamide and acetone. The concentration of nickel(II)hexacyanoferrate(II) in the matrix was $0.1-2.0 \mathrm{~mol} \mathrm{dm}^{-3}$, 
the concentration of dithiooxamide in the solution was $\left(\begin{array}{llll}3.0 & 10^{-3} & -5.0 & 10^{-2}\end{array}\right) \mathrm{mol}^{-1}$ and dithiooxamide: acetone molar ratio was kept equal to $1: 2$. The duration of the process was $10-12 \mathrm{~min}$ at $18-20^{\circ} \mathrm{C}$. An isolation of metalheterocyclic compounds formed in the matrix was carried out as it described in [1]. Found (\%): Ni, 15.4; C, 32.1; S, 33.7; N, 15.0; H, 3.6; $\mathrm{NiC}_{10} \mathrm{~N}_{4} \mathrm{~S}_{4} \mathrm{H}_{14}$, calc. (\%): Ni, 15.57; C, 31.85; S, 34.01; N, 14.86. Characteristic bands of the IR-spectra $\left(\mathrm{cm}^{-1}\right)$ : $680(v(\mathrm{C}=\mathrm{S})) ; 1650(v(\mathrm{C}=\mathrm{N}))$; 2865, $2950\left(v\left(\mathrm{CH}_{2}\right)\right) ; 3470(v(\mathrm{NH}))$. Molecular mass according to mass- spectroscopic analysis data is equal to 380 c.u. (calc. for $\mathrm{NiC}_{10} \mathrm{~N}_{4} \mathrm{~S}_{4} \mathrm{H}_{14}$ formula, 377,1 c.u.)

Synthesis of $\mathrm{Cu} C_{10} S_{\downarrow} N_{+} H_{!+}$. It was carried out as in the previous cases but on the contact with alkaline solutions $(\mathrm{pH}=11-12)$ containing dithiooxamide and acetone was copper(II)hexacyanoferrate(II) GIM. Found (\%): Cu, 16.4; C, 31.8; S, 33.0; $\mathrm{N}, 15.0 ; \mathrm{O}, 3.6 ; \mathrm{H}, 2.4 . \mathrm{CuC}_{10} \mathrm{~S}_{4} \mathrm{~N}_{4} \mathrm{H}_{1+}$, calc. (\%): Cu, 16.62; C, 31.45; S, 33.58; N, 14.67; H, 3.66. Characteristic bands of the IR-spectra $\left(\mathrm{cm}^{-1}\right): 680(\mathrm{v}(\mathrm{C}=\mathrm{S})) ; 1650$ $(v(\mathrm{C}=\mathrm{N})) ; 2860,2940\left(v\left(\mathrm{CH}_{2}\right)\right) ; 3470(v(\mathrm{NH}))$. Molecular mass according to massspectroscopic analysis data is equal to 385 c.u. (calc. for $\mathrm{CuC}_{10} \mathrm{~N}_{4} \mathrm{~S}_{4} \mathrm{H}_{14}$ formula, 381,9 c.u.)

The transmitted light absorbance of the GIMs $\left(\mathrm{D}^{-}\right)$were measured with a Macbeth TD504 photometer (Kodak Co., USA) in the 0.1-5.0 absorbance units range with an accuracy of $\pm 2 \%$ ( rel.). Electron absorption spectra of the GIMs were measured with using Specord UV-VIS (Karl Zeiss, Germany) spectrophotometer in the $400-800 \mathrm{~nm}$ range. UR-20 spectrometer (Karl Zeiss, Germany) was employed to record IR spectra.

\section{Results and Discussion}

The mathematical analysis of $\mathrm{D}^{-}=\mathrm{f}\left(\mathrm{C}_{\mathrm{F}}, \mathrm{C}_{\mathrm{L}}{ }^{0}, \mathrm{t}\right)$ kinetic curves of complexing where $D$ is the optical density of the metal-chelate GIM corresponding to concentration of metal(II) hexacyanoferrate(II) in the matrix $\left(\mathrm{C}_{\mathrm{F}}\right)$, dithiooxamide in solution $\left(\mathrm{C}_{\mathrm{L}}{ }^{0}\right)$ and the duration of the complexing process $t$ for the various dithiooxamide: acetone mo- 
lar ratio in the range $0.5-2.0$ carried out according to methodology [5], provides clear evidence that an addition of two dithiooxamide molecules and two acetone ones per $\mathrm{M}$ (II) ion occurs in the course of the process. The resulting compounds colour the polymeric masses of the GIM, which becomes brown $(\mathrm{Ni})$ or greenish-brown $(\mathrm{Cu})$. The UV-VIS-spectra of these compounds contain only a shoulder due to the intense charge transfer band, whose maximum is in the UV region. It should be noted that at in absence of acetone, in the case of $\mathrm{Ni}_{2}\left[\mathrm{Fe}(\mathrm{CN})_{6}\right]$, a violet compound $\left(\lambda_{\max }=580 \mathrm{~nm}\right)$ with spectral characteristics similar to those of the $\left[\mathrm{NiL}(\mathrm{OH})_{2}\right]$ complex $[2,3]$; in the case of $\mathrm{Cu}_{2}\left[\mathrm{Fe}(\mathrm{CN})_{6}\right]$, a dark-green substance with spectral characteristics similar to those of the known $\left[\mathrm{Cu}(\mathrm{HL})_{2}\right]$ chelate $[2,4]$ where $\mathrm{HL}^{-}$and $\mathrm{L}^{2}$ - are singly and doubly deprotonated forms of dithiooxamide, are formed. It is apparent that in the complexing process under examination, dithiooxamide as well as acetone participates. Decomposition of the polymeric binder of GIM according to the known procedure [1] allowed us to isolate dark-brown compounds $\mathrm{MC}_{10} \mathrm{~N}_{4} \mathrm{~S}_{4} \mathrm{H}_{14}(\mathrm{M}=\mathrm{Ni}, \mathrm{Cu})$. That important circumstance attracts its attention that oxygen is absent in the compositions of these substances; hence, acetone as a ligand cannot be in the inner coordination sphere of compounds under study. The compounds isolated are almost insoluble in water, ethanol, acetone, chloroform, benzene and tetrachloromethane, and poorly soluble in dimethylformamide, dimethylsulfoxide and hexamethylenephosphortriamide. $\mathrm{NiC}_{10} \mathrm{~N}_{4} \mathrm{~S}_{4} \mathrm{H}_{14}$ is diamagnetic and gives no ESR signal either at low $(77 \mathrm{~K}$, liquid nitrogen) or at room temperatures. This fact allows to assume that nickel in the compound indicated has an oxidation degree equal to +2 with planar $D_{2 h^{-}}$or $C_{2 h}-$ coordination of donor centers around nickel. The similar copper(II) compound is paramagnetic $\left(\mu_{e f f}=1.96 \mu_{\mathrm{B}}\right)$ and gives ESR signal with $g_{\|}=2.24, \mathrm{~g}_{\mid}=2.07$ which also typical for copper oxidation degree equal to +2 with planar coordination of donor centers to $\mathrm{Cu}(\mathrm{II})$ and the $\mathrm{N}_{2} \mathrm{~S}_{2}$ composition of these centers. The UV-VIS spectra of dimethylformamide solution of both compounds indicated are practically identical to those of their source GIM indicating that the immobilized compound is the same as that isolated from these immobilized matrices. The DTA data indicate that these 
compounds are very heat-resistant and do not undergo pyrolysis even at $600^{\circ} \mathrm{C}$. The IR spectra of the substances indicated have a band in the $3400-3500 \mathrm{~cm}^{-1}$ region typical of $\mathrm{NH}$ or $\mathrm{NH}_{2}$ groups uncoordinated to metal ion. Hence, at least a portion of the $\mathrm{N}$ atoms in these compounds are not bound to nickel or copper. The IR spectra of the compounds under examination contain $v(C=S)$ at $650-700 \mathrm{~cm}^{-1}$ (usually observed at $\left.705-570 \mathrm{~cm}^{-1}\right)$ and $v(\mathrm{C}=\mathrm{N})$ bands at $1640-1650 \mathrm{~cm}^{-1}$ (usually observed at 1690 $\left.1625 \mathrm{~cm}^{-1}\right)$ [6] indicating the presence of $(\mathrm{C}=\mathrm{S})$ and $(\mathrm{C}=\mathrm{N})$ groups, respectively. Unfortunately, the IR spectra obtained in the region $<1000 \mathrm{~cm}^{-1}$, where $v(\mathrm{M}-\mathrm{S})$ and $v(\mathrm{M}-\mathrm{N})(\mathrm{M}=\mathrm{Ni}, \mathrm{Cu})$ frequencies should be observed [6], do not allow us to reliably assign the bands they contain to the stretching vibrations indicated above. It should be especially noted that two medium-intensity peaks belonging to $v\left(\mathrm{CH}_{2}\right)$ (according to literature data [6], these bands lie within the $2945-2915$ and $2870-2845 \mathrm{~cm}^{-1}$ ranges, respectively). These bands are observed neither in the IR spectra of dithiooxamide nor in IR spectra of any the coordination compounds of $\mathrm{Ni}(\mathrm{II})$ and $\mathrm{Cu}$ (II) with this ligand known to date [6]. Thus, one may conclude that both compounds contain, as a minimum, one $\mathrm{CH}_{2}$ structural group. Since such groups are not present either in dithiooxamide, or in any of its complexes with $\mathrm{Ni}(\mathrm{II})$ and $\mathrm{Cu}(\mathrm{II})$, and acetone, as it is mentioned above already, and cannot be in the composition of metalheterocyclic compounds obtained, it is quite evident that the formation of complexes of metals indicated with some novel ligand which is «assembled» from dithiooxamide and acetone fragments, occurs during complexing in the $\mathrm{M}(\mathrm{II})$ - dithiooxamide- acetone systems $(\mathrm{M}=\mathrm{Ni}, \mathrm{Cu})$. It should be noted especially in this connection that the UVVIS absorption spectra of aqueous solutions of dithiooxamide of any concentrations in the range of 400-700 nm at $\mathrm{pH}>10$ did not change even on addition of significant amounts of acetone for at least 5 days, and no indications of a chemical process between dithiooxamide and acetone were observed. No doubt in this connection that the reaction between the reagents indicated above does not occur at all in the absence of a metal ion. A similar phenomenon is possible only where template synthesis takes place [7]. Besides, dithiooxamide and acetone act in it as ligand synthons. 
By taking into attention the all foregoing, we may conclude that an interaction between $\mathrm{M}(\mathrm{II})$, dithiooxamide and acetone in the $\mathrm{M}_{2}\left[\mathrm{Fe}(\mathrm{CN})_{6}\right]$-GIM proceeds according to the following scheme $(\mathrm{M}=\mathrm{Ni}, \mathrm{Cu})$ :

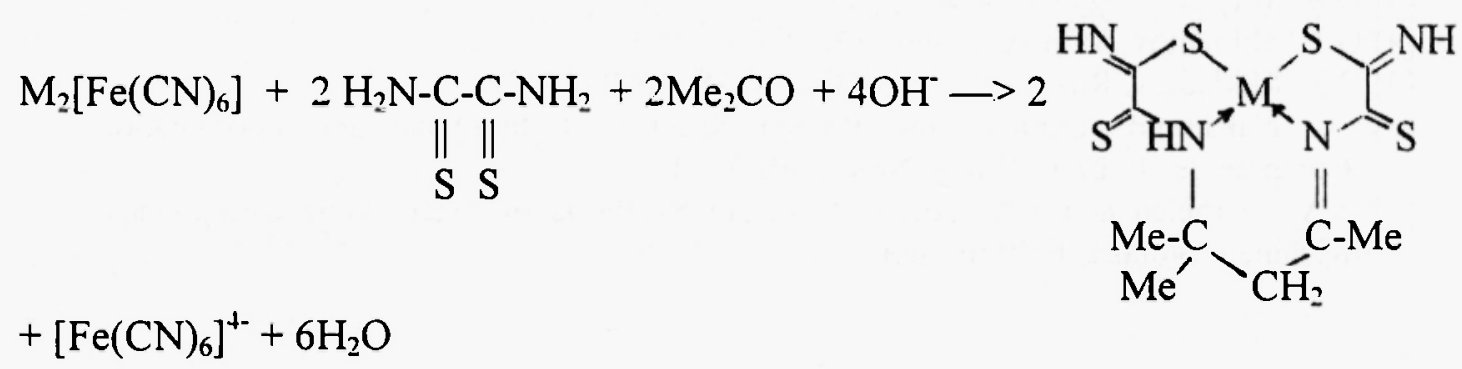

That circumstance attracts its attention that the final result of template synthesis between $\mathrm{M}(\mathrm{II})$, dithiooxamide and acetone differs from the final result of template synthesis between $\mathrm{M}(\mathrm{II})$, dithiooxamide and formaldehyde where metalheterocyclic compounds formed in the corresponding GIM contain $\mathrm{H}_{2} \mathrm{C}-\mathrm{O}-\mathrm{CH}_{2}$ groups [1]. Perhaps the cause of this distinction has been connected with distinctions of mechanisms of intramolecular dehydration which takes place in the course of the template synthesis process. This question has been not studied specially for the present.

It should be emphasized that processes of template synthesis between $\mathrm{M}(\mathrm{II})$, dithiooxamide and acetone as those between M(II), dithiooxamide and formaldehyde [1], occur only in gelatin-immobilized matrix; we failed to obtain these coordination compounds in the reaction of $\mathrm{Ni}_{2}\left[\mathrm{Fe}(\mathrm{CN})_{6}\right]$ or $\mathrm{Cu}_{2}\left[\mathrm{Fe}(\mathrm{CN})_{6}\right]$ (as $\mathrm{Ni}(\mathrm{II})$ or $\mathrm{Cu}(\mathrm{II})$ ) in solution or in the solid phase at room temperature.

\section{Acknowledgements}

Financial support from the Russian Foundation of Basic Research (Grants NN 96-03-32112 and 99-03-99212), from the Center of Fundamental Sciences of Ministry of Education of Russian Federation (Grant N 97-0-9.2-13) and from International Soros Science Education Program (Grant d98-176) is acknowledged. 
Refere nces

[1] O.V. Mikhailov. A.I. Khamitova and V.I. Morozov. Heterocyclic Comm. 6. 137 (2000)

[2] O.V. Mikhailov and G.K. Budnikov. Bull. Chem. Soc. Jpn, 62. 4016 (1989)

[3] O.V Mikhailov, Monats. Chem. 121, 601 (1990)

[4] O.V. Mikhailov, Monats. Chem., 122, 595 (1991)

.[5] O.V. Mikhailov, Russian J. Coord. Chem., 18, 1008 (1092)

[6] K. Nakamoto. Intrared and Raman Spectra of Inorganic and coordination Compounds. $4^{\text {th }}$ Edit. Wiley, New York, 1991.

[7] N.V. Gerbeleu and V.B. Arion, Template Synthesis of Macrocyclic Compounds. Kishineu, Stiintsa, 1990 (in rus).

Received on April 10, 2000 